\title{
Information and knowledge sharing trends of small and medium-sized enterprises in the Western Cape, South Africa
}

\begin{abstract}
Authors:
Faeda Mohsam ${ }^{1}$

Pieter A. van Brakel ${ }^{2}$

Affiliations:

${ }^{1}$ Faculty of Business, Cape

Peninsula University of

Technology, South Africa

${ }^{2}$ Faculty of Informatics and Design, Cape Peninsula

University of Technology,

South Africa

Correspondence to:

Pieter van Brakel

Email:

vanbrakelp@gmail.com

Postal address:

PO Box 652, Cape Town

8000 , South Africa

Dates:

Received: 25 Nov. 2010

Accepted: 19 Oct. 2011

Published: 29 Nov. 2010

How to cite this article: Mohsam, F. \& Van Brakel, P.A., 2011, 'Information and knowledge sharing trends of small and medium-sized enterprises in the Western Cape, South Africa', SA Journal of Information Management 13(1), Art. \#462, 10 pages. http:// dx.doi.org/10.4102/sajim. v13i1.462
\end{abstract}

C) 2011. The Authors. Licensee: AOSIS OpenJournals. This work is licensed under the Creative Commons Attribution License.
Background: Small and medium-sized enterprises (SMEs), especially in the Western Cape Province of South Africa, are currently facing various financial and other obstacles, which may threaten their survival. Globalisation, the lowering of trade barriers and the reduction of import tariffs have resulted in increased international competition. Businesses are thus forced to undertake continuous improvements and innovation in order to survive, to keep abreast of change and to excel.

Objectives: Effective knowledge sharing and consequent knowledge management (KM) have been identified as definite approaches to enhancing competitive advantage. The research therefore aimed to establish to what extent small enterprises embrace their knowledge sharing activities and whether their knowledge sharing activities are managed at all. Furthermore, it examined how their knowledge sharing can contribute to their competitive advantage.

Method: A case study approach was followed for this research. Selected SMEs from the engineering sector were the subject of the case study and SME owners, directors and managers of consulting civil engineering firms were interviewed to determine whether there are mechanisms in place to ensure better knowledge sharing within SMEs.

Results: In general, respondents had stated that they possessed special factors that set them above their competitors:

- The company strategy and good reputation of completing projects within the required timeframe. In other words, they were well known for their track record in terms of service delivery.

- Their specialty in terms of different focus areas, namely structural and civil engineering, water supply and storm water design, transportation, sewer design and storm water traffic.

- The fact that they operated in silos. This means that the specialists in their specific fields operated independently in groups, separately from everyone else in the company.

- Their good relationship with local authorities and other companies in the field.

- Their multidisciplinary approach in incorporating all spheres of civil engineering, which gave them a niche in the market.

- The vast knowledge and experience of the owners and directors.

Conclusion: Each of the companies interviewed had unique skills that they can apply to their advantage. They were also found to be implementing KM processes such as sharing, creating and leveraging of information and knowledge, albeit in the absence of formal policies. It was therefore deduced that SME successes depend on how well they share their tacit and explicit knowledge; this will determine whether they would excel above their competitors.

\section{Introduction}

Small businesses form an integral part of the South African economy. The importance of the small business sector is widely recognised and it is therefore essential that small businesses survive and prosper. According to the South African Department of Trade and Industry, by 2004 approximately $45 \%$ of employed people in South Africa worked in the small business sector and it is predicted that this sector could contribute up to $60 \%-80 \%$ of the gross domestic product over the next 5-10 years (South Africa business guidebook 2006:241). The importance of small business is stressed repeatedly in the important policy publication of the South African Government, namely A framework to guide Government's programme in the electoral mandate period 2009-2014 (South African Government 2009).

In South Africa, the National Small Business Act (Act No. 102 of 1996) defines micro, small and medium businesses (SMMEs) as: 
... a separate and distinct business entity, including co-operative enterprises and non-governmental organizations, managed by one owner or more which, including its branches or subsidiaries, if any, is predominantly carried on in any sector or sub-sector of the economy ... and which can be classified as a micro-, a very small, a small or medium enterprise by satisfying the criteria ... opposite the smallest relevant size or class ...

(South African Government 1996)

The Act further defines a small business organisation as:

... any entity, whether or not incorporated or registered under any law, which consists mainly of persons carrying on small business concerns in any economic sector, or which has been established for the purpose of promoting the interest of or representing small business concerns, and includes any federation consisting wholly or partly of such association, and also any branch of such organization.

(South African Government 1996)

For the purpose of clarification, the term 'SMME' is one that is used only in the South African context, whereas 'SME' is mostly an international term that encompasses our SMME concept. In this article 'SME' is therefore preferred and will be used throughout.

In South Africa, there are presently approximately two million small, medium and micro enterprises (SMEs) registered to create long-term employment (South African Government 2009). Nearly a decade ago, Berry et al. (2002:4) already positively indicated the major economic roles SMEs fulfil in South Africa, for example, by manufacturing goods of value or by providing services to both consumers and or enterprises. SMEs also contribute to export performance by offering services and products to foreign clients. Akinwumi and Olawale (2010:2763) assert that, as a result of South Africa's current high unemployment rate, SMEs are expected to be an important mechanism to address the challenges of job creation, economic growth and development. They further state that SMEs are an important source of innovation when it comes to new products, services and technology. It is therefore clear that both small and medium enterprises play a significant role in the South African economy.

\section{Research problem}

From the above it is clear that SMEs can play a pivotal role in any national economy. Furthermore, for the purpose of this research, it was assumed that the continued successes of SMEs might further be improved if their knowledge sharing practices are placed on a sound footing. This assumption is line with the views expressed by Antoncic and Omerzel (2008:1184), namely that the management of knowledge assets may be critical to provide small companies with new tools with which to survive, grow and maintain a sustainable competitive advantage. Because knowledge has become one of the most important driving forces for business success, companies are becoming more knowledgecentred, focusing more on hiring 'minds' rather than 'hands' to facilitate the increasing need for leveraging knowledge (Wong 2005:261). From the above-mentioned statements, it is clear that knowledge is the one asset with which a company can distinguish itself from its competitors. This also implies that knowledge, although intangible, is being treated as a resource and therefore as a means of improving and maintaining competitive advantage. The objective of this research is therefore to determine the nature and extent of SMEs' knowledge-sharing practices in the Western Cape Province. If these sharing practices could be identified and nurtured, any particular SME could be in a better position to gain competitive advantage over its competitors.

\section{Research methodology}

The research conducted was qualitative in nature and a case study approach was followed. Ten small and medium enterprises were studied and interviews were conducted for data collection purposes with a selected number of participants from the consulting civil engineering industry. Stead and Struwig (2001:8) believe that this method of research is not used often enough as it entails an in-depth study of a small number of situations or cases. However, its main purpose is to provide a complete description and understanding of the matter that is studied, notwithstanding the small number of people involved. These authors (2001:8) also state that three important factors normally are identified in this type of study, namely:

- features that are common to all cases in the general group

- features that are not common to all cases, but are common to certain subgroups

- features that are unique to specific cases.

In this regard, it was argued that the case study approach should provide the researcher with a clear understanding of the current status of knowledge-producing processes within the enterprise. Both illustrative and experimental case study approaches were used amongst small and larger enterprises in order to determine the extent to which knowledge practices were adopted within SMEs and the potential contribution of these practices to improving competitive advantage. In this way, the researchers could perhaps create a clearer picture of the status of knowledge sharing in SMEs.

The civil engineering sector was chosen for the purposes of this study because it is characterised as a highly specialised, knowledge-intensive and project-based industry within the Western Cape. Maintaining competitive advantage in this regard is therefore of the utmost importance in this category of enterprises. After careful consideration, 10 SMEs from the civil engineering sector in the Western Cape were selected. An initial pilot study was conducted with three small and medium-sized companies in the construction and consulting engineering field to establish the validity of the questionnaire that had been created in view of establishing the nature of knowledge sharing. However, it was decided to limit the research to only the consulting civil engineering sector as the two spheres of engineering (constructing and consulting) have quite different work practices. More information regarding the companies interviewed, their core business and the number of employees in each is listed in Table 1. 
TABLE 1: List of consulting engineering companies interviewed.

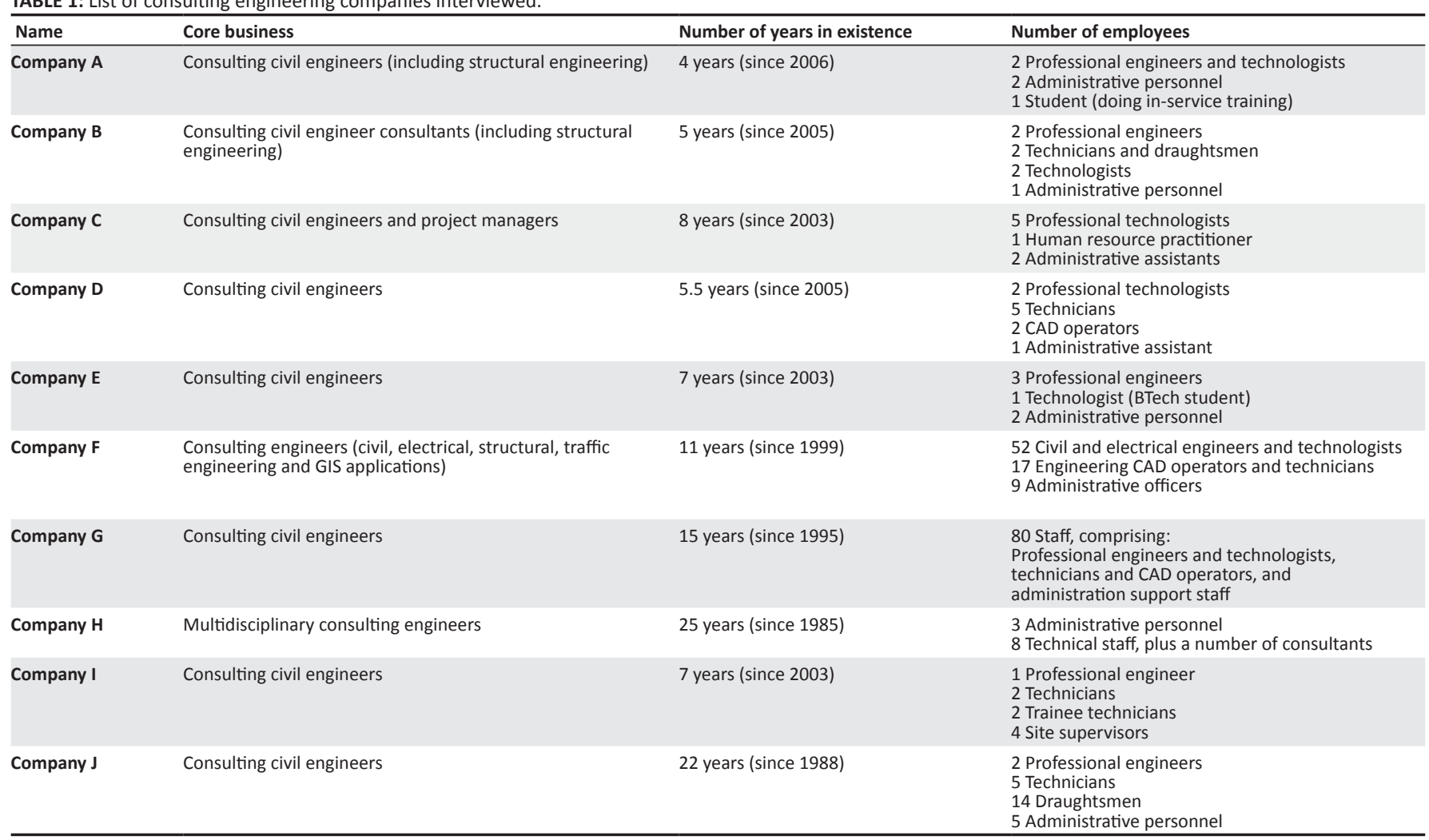

CAD, computer-aided design; GIS, geographic information system.

As mentioned above, in-depth interviews were conducted with the owners, directors and senior staff of selected SMEs. All interviews were manually recorded and a case study was written for each SME. The structured questionnaire (see Appendix Interview Questionnaire) was designed under the following broad categories:

- Section A: Biographical and company information, including organisational structure and outline of employees. This was needed to determine the type of company, as well as the categories of staff according to professional, technical and administrative abilities.

- Section B: Knowledge and information sharing practices. This was necessary to establish, inter alia, what challenges the various companies' face, their modes of communication with staff, whether there was a culture of trust amongst management and employees to facilitate the sharing of knowledge, training and mentoring, and whether succession-planning measures were in place.

- Section C: Information needs and knowledge sources. This was important for establishing the companies' information needs and information retrieval techniques.

- Section D: Management of knowledge and acquisition of external information. Answers to questions in this section would identify, inter alia, whether there were alliances in place with partners to gain external knowledge and expertise, the type of organisational structure used by the companies, the use of various storage and retrieval techniques, the use of information technology and information systems, the companies' research and development activities, the extent of their face-to-face communication and social networking practices, and any affiliations to professional bodies.
- Section E: The level of competitive advantage (CA). This included information on what sets these companies apart from their competitors, their strategy with regard to achieving CA, their efforts to increase market share, efficiency and gain CA, who their competitors are and whether they knew what their competitors were up to, who their customers are, and the extent to which they valued their customers.

- Section F: The combination of knowledge management and competitive advantage practices. Similarly, information about the combination of these practices was needed to identify if and how company knowledge was managed, whether the company promoted a KM-friendly environment, organisational practices with regard to KM, whether they knew what type of marketing activities rival companies undertook with regard to their increasing CA, what they did to increase their own CA, and how they used their knowledge to gain CA.

Some questions from previous prominent KM studies were extracted and modified for the purposes of this study, for example, those undertaken by authors such as Kok, Van Brakel and Van der Walt (2004), Snyman and Van der Berg (2003) and Uit Beijerse $(1999,2000)$ (see Appendix Examples of previous knowledge management studies that have been undertaken).

The next section briefly discusses the current status of KM implementation in SMEs globally, thereafter the methodology of this is described in more detail and the results of the current research are interpreted. 


\section{Brief overview of knowledge management in small and medium enterprises}

It is common knowledge that KM was originally mostly practiced in larger enterprises, with specific foci on issues such as culture, networking, and the development of organisational and technological infrastructures to accommodate KM initiatives, especially in large multinational environments. Awazu and Desouza (2006:40) assert that SMEs knowingly or unknowingly manage knowledge intuitively in the right way, that is, the humanistic way, whilst Furu, Salojarvi and Sveiby (2005:104) contend that although KM is practiced in small companies, SME managers do not necessarily know it as such, or call it knowledge management. Similarly, Uit Beijerse's (2000:175) study on 12 innovative small companies in the Netherlands found no less than 79 different $\mathrm{KM}$ activities in these businesses. According to the same source, this was owing to the fact that SMEs have emerged as a business paradigm in today's knowledge economy. However, SME successes, and ultimately their growth, will determine to what extent they manage their knowledge work and thus knowledge sharing.

According to a recent study, many SME managers in Germanspeaking countries have come to realise and appreciate that the inventiveness and uniqueness of each of their knowledge workers would lead to customer satisfaction, as well as the success of the SME (Fink \& Ploder 2009:37). Although these SMEs were often cash-strapped and did not have enough capital to invest in KM initiatives, it was necessary for them that their knowledge was leveraged optimally in order to achieve most of the goals of the enterprise. Fink and Ploder's (2009) research also emphasises the importance of capturing individual and organisational knowledge, which could result in gaining CA in SMEs, predominantly because human capital is the source of creativity in enterprises. Consequently, it is also imperative that a typical small enterprise's implicit or tacit knowledge should be converted to explicit formats in order to perform, store and retrieve functions to enhance organisational value (Bozbura 2007:210). In order to achieve this, enterprises should invest in their employees by means of training and mentoring. In other words, for KM to be successful, employees optimally should share both tacit and explicit knowledge and information within the organisational memory base. Tacit knowledge, which is regarded as a key ingredient of socially constructed knowledge, is primarily captured by means of informational discussions in whichever formats. Because this knowledge resides within the minds of people and is therefore difficult to formalise, transfer or spread, it cannot be thought of or argued about in the same way as explicit knowledge. Thus, it seems less complicated to apply KM processes in small and medium companies because it is easier to capture tacit knowledge in less formalised (small) environments such as SMEs.

In his research on KM practices in Turkish SMEs, Bozbura (2007:211) emphasises the importance of capturing and acquiring knowledge, which is gained by arranging and managing an organisation's relationship with its customers, shareholders, suppliers, rivals, the state, the official institutions, society, and so on. His research reveals that their success can be attributed to four factors:

- training and mentoring of employees

- policies and strategies of KM

- knowledge capturing and acquisition from outside

- effects of organisational culture.

Empirical evidence from research conducted by Chen et al. (2006:20) should also be taken in account. This research was undertaken amongst British SMEs in the service sector to identify their needs and practices regarding interorganisational knowledge transfer. It showed that external knowledge was of paramount importance for SMEs. Their research also showed that customers had the biggest impact on SMEs and thus it is imperative for SMEs to develop and maintain good customer relationship management practices. Holding regular meetings with main customers and suppliers, obtaining advice from counterparts in other organisations and dealing with complaints, as well as engaging in social and electronic networking, are some of the ways in which inter-organisational knowledge transfer can take place in SMEs.

Massa and Testa (2008:2) state that although information and data management are important aspects of $\mathrm{KM}$, the latter involves broader issues, such as the creation of processes and behaviours that allow people to transform information within the organisation to enable them to create and share knowledge. Therefore, it is imperative that KM in SMEs should also include people, process, technology and culture.

Du Plessis's research (2008:61-66) on the impact of communities of practice (CoPs) as vehicles for knowledge sharing in SMEs revealed that CoPs can be an effective KM tool for SMEs. Du Plessis (2008) defines CoPs as groups of people who work together with the aim of achieving specific goals by means of creating, sharing and leveraging information. Although these groups of people are often from different backgrounds, they can work together towards achieving a common goal, using their knowledge, skills and abilities to achieve this. They also share a common concern or passion for what they do and each one brings unique skills to the CoP, which are then shared amongst members of the community. These members do not necessarily work together on a daily basis, but they benefit and find value in their regular meetings and interactions. They share information, insight and advice, explore new ideas and often act as sounding boards for one another. CoPs can be either technologically advanced, for example, they may use particular management systems, or they could be simplistic in nature, such as a group of like-minded people discussing a work-related problem, or seeking a solution with minimal or no use of technology. Some of the points extracted from Du Plessis's (2008:61-66) research focus on knowledge sharing and how CoPs can impact on SMEs in this regard, for example, (1) CoPs can assist in managing the knowledge 
sharing life cycle and (2) CoPs can serve as vehicles to combat knowledge loss.

Du Plessis's research shows the enormous impact that CoPs can have on SMEs, emphasising the fact that knowledge is a definite factor for CA within SMEs. In this research project, the researchers therefore also aimed to establish whether they could assist with the creation, sharing and leveraging of knowledge in these smaller communities, as well as whether they could assist these communities to cope with knowledge losses when employees retire or leave the organisation. These and other research findings are discussed below.

\section{Findings, analysis and interpretation Knowledge and information sharing practices (Interview questions B1-6)}

As mentioned above, SMEs in general face a number of financial and other challenges. This also emerged during the interviews (see Appendix Interview Questionnaire for the specific questions in this regard), with the three biggest challenges seeming to be the following:

\section{Attracting good quality staff and staff retention}

It was apparent that staff retention is always a challenge in any small business environment as many employees were often lost to larger companies who offered higher salaries and more benefits, which SMEs found difficult to match. Qualified engineers seemed to start their careers in small businesses, but were often lured away by the salaries offered by larger organisations. Some engineers often specialised in a particular area and once they gained enough experience, they moved on to larger organisations. A large portion of respondents cited access to finance as another challenge for SMEs.

\section{Finance}

Fierce competition was identified as a predominant factor for SMEs during the past 5 years (and earlier), as many enterprises tendered at substantially lower prices, which made it difficult for others to compete. It was therefore important for them to distinguish themselves as being preferred providers in the industry, not only in terms of the prices that they offered for their services, but also in terms of having expert knowledge and using this knowledge to their competitive advantage.

The findings highlighted the importance of creating a culture in which the sharing of knowledge is encouraged, supported and promoted by management. Although informally approached, a definite culture of sharing and trust amongst management and staff was found amongst the companies within this study and, in this way, the sharing of knowledge, both tacit and explicit, was facilitated, for example, by means of hands-on training, focused staff discussion and debriefing sessions. The findings also showed the importance of converting tacit knowledge into explicit knowledge in order for it to have added value. This ensured that if a skilled person retires or leaves the company, some of those skills would remain with the company. One of the ways in which tacit knowledge was shared was by means of informal debriefings and the less formalised structure of SMEs provided unique platforms where these informal discussions could take place. Additionally, the findings emphasised the importance of these companies' knowledge assets, which included their past projects, processes and procedures, competitor information and drawings that were captured and retained in the corporate memory, such as within databases, portals and digital libraries, to facilitate the retrieval thereof. In this way, these knowledge assets could be used and leveraged to the companies' advantage. Training of staff and mentoring were distinguishing factors that contributed to the effective management of the SMEs and enabled their staff to work together as a cohesive unit in which staff felt appreciated and valued. In this way, staff performance was enhanced, which ensured that an enterprises' strategic objectives were realised, which could eventually lead to gaining CA. From our research it is clear that most SMEs definitely implement $\mathrm{KM}$ processes, albeit in an informal and very intuitive basis.

In terms of information and knowledge sharing practices, it can therefore be concluded that:

- Some of the major challenges faced by SMEs are, (1) attracting good quality staff, (2) retaining staff and (3) finance.

- SMEs were generally well managed, which was largely owing to the more relaxed and informal atmosphere that is prevalent within them. SMEs consisted of cohesive, well organised teams that worked together as a single unit.

- There was a culture of trust amongst management and staff that facilitated the sharing of knowledge. Platforms were created where staff could come together to share tacit knowledge. These included hands-on training on site and dedicated weekly report back sessions.

- There was an effective flow of communication between management and staff.

- If a highly skilled employee were to leave their employ, it was not always seen as a total loss, as there were measures in place to cope with such a loss. This was due to the fact that most of the knowledge resided with the owner or director and was also transferred to others within the company by means of mentoring and handson training. Some enterprises had joint ventures with other companies; hence, they could tap into the resources of their competitors. Two of the companies (Companies $\mathrm{D}$ and $\mathrm{H}$ ) were multidisciplinary, which meant that they had experts in all the engineering spheres and the loss of a skilled staff member was easily absorbed.

- Knowledge was shared, even in the absence of a formal policy. This proved that there was a definite culture of sharing and trust amongst management and staff.

- Succession planning was a problem, however, as only a few respondents (Companies D, F and J) had identified senior staff as likely succession candidates, but there were no formal measures in place. 


\section{Information needs and knowledge sources (Interview question C1)}

Respondents were asked about their information needs and knowledge sources, as well as how often they had to search for information in order to establish the extent of their explicit knowledge base. All respondents stressed that their information needs were industry-specific. In other words, they worked according to SABS-approved standards and specifications. They all stated that whilst the Internet was their main source of information with regard to their projects, they often referred to their clients' standard documents for information and guidelines, for example, the Provincial Government of the Western Cape, which is their biggest client, has its own design guidelines. Companies $\mathrm{C}, \mathrm{D}$ and $\mathrm{F}$ obtained information from their own digital libraries, which they have built up over a period of time, for example, Company E was a member of the American Society of Mechanical Engineering and had access to this society's library. Other sources of information were civil engineering journals and magazines - for example, the International Journal of Green Energy or Engineering News - engineering textbooks for referencing, and product manuals. Companies $A$ and $G$ also cited other specialists in the industry (engineers and academics) as sources of information.

All respondents stated that they do not have to search for information on a regular basis, but when they did, their first port of call was the Internet. They were seldom bombarded with loads of information as their information needs were industry-specific and they often found what they are looking for without having to conduct lengthy searches. Thereafter, they would consult other sources such as digital libraries, manuals, engineering journals and textbooks, as well as experts who have the relevant experience from within industry.

Companies $\mathrm{C}$ and $\mathrm{D}$ had intranet access to a document management system where pro-forma documents, templates, policy guidelines and other information regarding projects were stored. Others (Companies C, D and F) had built up internal traditional and digital libraries over the years, which served as a good source of information. Information in this regard was stored in a manner that facilitated easy retrieval.

Therefore, from the above it is clear that:

- The information requirements of various companies were basic because they worked according to approved SABS standards and specifications.

- Most of their information could be retrieved from their own paper collections and digital libraries, as well as learning from the knowledge of experts within the industry itself.

\section{Management of knowledge and acquisition of external information (Interview questions D1-7)}

Although indirectly applied, it was clear from the interviews that information and knowledge per se was seen as a very important driving force for business success. The acquisition of external information, as well as the storage and dissemination of internally generated information, was important to the SMEs interviewed. The attendance of conferences, forums and seminars created a platform where staff could network and collaborate with peers and other experts in the field. At these platforms, people from diverse business backgrounds were able to meet, make initial contact and extend their own networks. External information was also gained from conferences arranged by major manufacturers. Attendees were then exposed to the latest market trends in engineering and this could lead to further collaboration with manufacturers. It was found that the senior staff members, especially, would arrange not only formal but also informal meetings or workshops to provide feedback (knowledge sharing) of what they acquired at these conferences. The findings also highlighted the importance of networking in a competitive market. If these networks, which consisted of people with specialised skills and expertise, could be nurtured, it could facilitate the dissemination of tacit, as well as explicit, knowledge and ultimately could enhance or support CA for a particular small or medium enterprise.

\section{To summarise:}

- External information and knowledge (explicit and tacit) was gained through conference, seminar and forum attendance, where staff networked and collaborated with peers and other experts in the field. The majority of companies - except for Companies A and D -indicated that their staff attend conferences or seminars at least twice a year.

- Companies F, G and H indicated that was imperative for them to maintain their membership of professional bodies such as the Engineering Council of South Africa. There is a rewards system in place whereby members are awarded a number of points for attending conferences and seminars, as well as for attending training courses and mentoring of students.It was vitally important for companies to determine the nature of the information and knowledge that they need in an effort to gain and maintain CA. Typical information and knowledge acquiring needs that were identified were, inter alia, about dams and multistorey structures, geometrics technology, and road design.

\section{The level of competitive advantage (Interview questions E1-8)}

All respondents had special knowledge and skills that could provide them with a competitive edge, which is an important aspect for their survival in this highly competitive field. They all strive to provide their clients with expert service and personal attention. Owners and directors of the companies had diverse backgrounds in the fields of business and academia and this reflected in their company strategy, as their staff and competitors were able to tap into their vast fields of knowledge and expertise. Because of the small and intimate nature of the consulting civil engineering field, and combined with the fact that they are well known amongst their peers, they were often seen as the preferred service provider in the field by both the City of Cape Town and private clients. 
From the findings, it can be deduced that the implementation of $\mathrm{KM}$ processes could lead to $\mathrm{CA}$ and, in the case of the SMEs that were interviewed, we found that their expert knowledge and skills gave them a competitive edge. Because of the diverse backgrounds of owners and directors of the companies, not only in the field of business, but also in terms of academia, they often possessed expert knowledge and other consulting companies would consult with them or tap into their expertise. Owing to the fact that the consulting engineering field is small and they were well known amongst their peers for their expertise, they were often preferred service providers. This is important for their survival in this highly competitive field. They had also established themselves as preferred providers in the industry and this was owing to the fact that they had established strategies to achieve and maintain their CA. This could be further enhanced through effective marketing, which was lacking in SMEs.

In terms of CA, therefore:

- All respondents had special knowledge and skills that, if constantly developed, would provide them with a competitive advantage.

- They all had established strategies to achieve and maintain CA.

- All respondents indicated that they had achieved some or all of their objectives. For example, an important objective of Companies F and G was the employment of historically disadvantaged individuals.

- Many believed that they could still achieve more in order to gain and maintain CA.

- A concern was that few respondents engaged in any formal marketing activities. Companies B and $G$ were the only companies that engaged in some form of marketing. Reasons cited for the lack of marketing included lack of time and lack of finances. They all agreed that it was a priority and placed it on their list of priorities for 2011.

\section{The combination of knowledge management and competitive advantage practices (Interview questions F1-4)}

Because the engineering sector was regarded as being highly project-based, it was important for information and knowledge to be managed in a way that could favour the CA of a particular enterprise. In other words, information and knowledge should be captured and stored in a way that would simplify retrieval and dissemination, especially if they had to refer to previous but similar projects. It was also an imperative for such information and knowledge to be accessible to everyone in the company. It was evident from the findings that sound information and knowledge sharing processes were not yet in place with regard to the majority of enterprises interviewed. It was also clear that not many avenues were utilised to capture and share tacit knowledge. As an example, only one company (Company J) had a paperbased site instruction book where experiences and ideas could be recorded and stored for future use. No electronic means to share knowledge (for example a company network) was utilised by any of the enterprises. Some of the other means of sharing tacit knowledge was through hands-on training, but was not made explicit. This is largely a result of the fact that no formal KM policy was in place in any of the enterprises. The recording of valuable information was found to be vitally important and could help to preserve the companies' expertise, especially in view of the fact that staff retention is one of main the problems experienced by SMEs. This is also important because succession planning does not seem to be a priority amongst SMEs.

In order to remain competitive, it is important for companies to know what their competitors are doing. Owing to a lack of marketing activities in almost all of the companies that were interviewed, few of them knew, in detail, what their competitors do to stay ahead in the field. Companies E and J were involved in joint ventures with their competitors and, to this extent, they had some knowledge of what others in the industry were doing. The consulting civil engineering field is close-knit and because they compete amongst themselves and not with large companies, the only knowledge they had about one another concerned tender prices. In other words, they were able to estimate which company had tendered at what price. Even so, this information was often obtained through the 'grapevine' or via notices in the local newspaper, which could be attributed to the fact that not much research was undertaken regarding their competitors' operations.

The above findings show that although it is important for companies to know how their competitors operate in order for them to improve their services, their efforts to stay abreast of this information were not that impressive. Improvements in this regard could be achieved through effective marketing or by, for example, appointing a dedicated staff member to browse or scan news sources for competitor achievements. The civil engineering field is fairly small in the Western Cape and it is important for companies to have that special feature that sets them apart from their competitors and which ultimately ensures them a competitive advantage in the field. When questioned about this, respondents mentioned the following features or strong points, which 'set them apart from their competitors':

- The company strategy and good reputation of completing projects within the required timeframe. In other words, they were well known for their track record in terms of service delivery.

- Their specialty in terms of different focus areas, namely structural and civil engineering, water supply and storm water design, transportation, sewer design, or storm water traffic.

- The fact that they operated in silos. This means that specialists in their specific fields operated independently in groups, separately from everyone else in the company.

- Their good relationship with local authorities and other companies in the field.

- Their multidisciplinary approach in incorporating all spheres of civil engineering, which gave them a niche in the market.

- The vast knowledge and experience of the owners and directors of the enterprises. 
The majority of respondents agreed that they had the right people in the company in order to achieve CA. The majority of Company H's staff comprised consultants who also had other priorities and, as such, their time was divided between their company and other companies. Some therefore preferred to employ retired consultants who would be able to give their full attention to the company. Many cited their staff as one of their most important organisational assets. Coupled with this, the expert knowledge of both the owners and staff of SMEs played a prominent role in achieving and maintaining $\mathrm{CA}$. When questioned about the ways and means in which their knowledge contributed to their CA, some of the answers the companies provided were as follows:

- Their vast experience in working for local government, as well as municipalities, gave them good knowledge of government processes and procedures, particularly because the City of Cape Town is their largest client.

- The extensive personal knowledge and experience of directors in areas of business and academia was a major factor. This knowledge was shared and disseminated throughout the company though hands-on training and mentoring, making it easy for the enterprise to operate in the absence of the director or owner when he or she is away for any length of time. The director of Company $\mathrm{F}$ stated that he often shared his expertise with competitors and did not see this as a threat to his own business, as the sharing of knowledge served to strengthen the engineering sector as a whole.

- Many companies 'grew their own timber' - this meant that students who did their in-service training at the company were often offered a full-time position. Such staff members would have been mentored by the owner or director and were therefore able to plough their skills back into the company. In this way their expertise was grown in-house, which also ensured that most of the work was done in-house. In addition, this process allowed for tacit knowledge to pass from owner or director to staff member.

- Their various areas of expertise, which allowed them to establish a niche in the market, were major competitive tools that made them preferred providers in the industry.

\section{Conclusion}

Results from the research show that most SMEs do not have formal policies or procedures in place to align their strategic objectives. Also, although a number of KM practices came to the fore, no formal information and knowledge sharing practices exist as yet. However, it was also found that good but informal, or rather unstructured, communication means exist between management and staff. The sharing of information and knowledge (both tacit and explicit) was encouraged by means of dedicated forums and hands-on training and there was a definite culture of trust amongst management and staff, which facilitated the sharing of tacit knowledge. It was clear that the SMEs that were interviewed actively used information technology to capture, store and disseminate knowledge, which they could then use to achieve and maintain CA. All of the companies had measures in place whereby knowledge was captured and stored to simplify retrieval thereof, whether tacit or explicit. However, none of the companies that were interviewed already made use of Web-based or social networking tools in order to share information and knowledge effectively. When interviewed, some respondents acknowledged the importance of these tools and the fact that they would be an important vehicle to facilitate better knowledge sharing in SMEs; SMEs could benefit from the establishment of social networking.

The research also indicated that competitive advantage stems from a company's unique knowledge warehouse. The management of such a unique knowledge base, therefore, has the potential to make enterprises more competitive and profitable. The combination of competitiveness and profitability can lead to high-margin niche markets. However, in order to achieve and maintain CA, companies should distinguish themselves not only in terms of the service that they offer, but also in terms of the type of information at their disposal. In order to achieve this they should have a distinct information and knowledge policy in place.

Further research is necessary to establish how modern knowledge sharing approaches and technologies can best be implemented in the typical small and/or medium enterprise. The availability of the Internet will have a profound impact on the way in which these enterprises can share their tacit and explicit knowledge.

\section{References}

Akinwumi, O. \& Olawale, F., 2010, 'The determinants of access to trade credit by new SMEs in South Africa', African Journal of Business Management 4(13), 2763-2770, viewed 17 January 2011 from, http://www.academicjournals.org/AJBM

Antoncic, B. \& Omerzel, D.G., 2008, 'Critical entrepreneur knowledge dimensions for the SME performance', Industrial Management \& Data Systems 108(9), 1182-1199, viewed 18 March 2011, from http://www.emeraldinsight. com/10.1108/02635570810914883

Awazu, Y. \& Desouza, K.C., 2006, 'Knowledge management at SMEs: Five peculiarities', Journal of Knowledge Management 10(1), 32-43, viewed 02 June 2009, from http://www.emeraldinsight.com/10.1108/13673270610650085

Berry, A., Von Blottnitz, M., Cassim R., Kesper, A., Rajaratnam, B. \& Van Seventer, D.E., 2002, The economics of SMMEs in South Africa in trade and industrial policy strategies, viewed 19 November 2008, from http://www.tips.org.za/files/506.pdf

Bozbura, F.T., 2007, 'Knowledge management practices in Turkish SMEs', Journal of Enterprise Information Management 20(2), 209-221, viewed 02 June 2009, from http://www.emeraldinsight.com/10.1108/17410390710725788; http://dx.doi. org/10.1108/17410390710725788

Chen, S., Duan, Y., Edwards, J.S. \& Lethaney, B., 2006, 'Toward understanding interorganizational knowledge transfer needs in SMEs: Insight from a UK investigation', Journal of knowledge management 10(3), 6-23, viewed 02 June 2009 from http://www.emeraldinsignt.com/10.1108/13673270610670821; http://dx.doi. org/10.1108/13673270610670821

Du Plessis, M., 2008, 'The strategic drivers and objectives of communities of practice as vehicles for knowledge management in small and medium enterprises International Journal of Information Management 28(1), 61-67, viewed 08 April 2011, from http://www.elsevier.com/locate/ijinfomgt; http://dx.doi. org/10.1016/j.ijinfomgt.2007.05.002

Fink, K. \& Ploder, C., 2009, 'Balanced system for knowledge process management in SMEs', Journal of Enterprise Information Management 22(1/2), 36-50, viewed 02 June 2009, from http://www.emeraldinsight.com/Insight/viewContentltem. do;jsessionid=4C39A55B2; http://dx.doi.org/10.1108/17410390910922813

Furu, P., Salojarvi, S. \& Sveiby, K.E., 2005, 'Knowledge management and growth in Finnish SMEs', Journal of Knowledge Management 9(2), 103-122, viewed 02 June 2009, from http://www.emeraldinsight.com/10.1108/13673270510590254

Kok, J.A., Van Brakel, P.A. \& Van der Walt, C., 2004, 'Knowledge sharing via enterprise intranets - Asking the right questions', South African Journal of Information Management 6(2), viewed 23 March 2007, from http://www.sajim.co.za/default. asp?to=peer3vol6nr4

Massa, S. \& Testa, S., 2008, 'A knowledge management approach to organizational competitive advantage: Evidence from the food sector', European Management Journal 27(2), 129-141, viewed 26 June 2009, from http://www.elsevier,com/ locate/emj 
Snyman, M.M.M. \& Van der Berg, H., 2003, 'Managing tacit knowledge in the corporate environment: Communities of practice', South African Journal of Information Management 5(4), viewed 23 March 2007, from http://www.sajim. co.za/default.asp?to=peer3vol5nr4

South Africa business guidebook 2004-2005, 2006, 'Small, medium \& micro enterprises (SMMEs)', 9th edn., pp. 241-243, 3SMedia, viewed 24 July 2006, from http://www.journals.co.za/ej/ejour_ws sabg.html

South African Government, 1996, National Small Business Act No. 102 of 1996, South African Government, Pretoria, viewed 26 June 2009, from http://www.info.gov. za/view/DownloadFileAction id=70848

South African Government, 2009, Together doing more and better - Medium term strategic framework: A framework to guide Government's programme in the electoral mandate period 2009-2014, The South African Presidency, Pretoria, viewed 15 September 2011, from http://www.thepresidency.gov.za/docs/pcsa/ planning/mtsf_july09.pdf

Stead, G.B. \& Struwig, F.W., 2001, Planning, designing and reporting research, Maskew Miller Longman, Cape Town.

Uit Beijerse, R.P., 1999, 'Questions in knowledge management: Defining and conceptualising a phenomenon', Journal of Knowledge Management 3(2), 94-109, viewed 10 June 2009, from http://www.emeraldinsight.com/Insight/ viewContainer.do?containerType=Issue\&containerld $=16017$

Uit Beijerse, R.P., 2000, 'Knowledge management in small and medium-sized companies: Knowledge management for entrepreneurs', Journal of Knowledge Management 4(2), 162-179, viewed 02 June 2009, from http://www. emeraldinsight.com./10.1108/13673270010372297

Wong, K.Y., 2005, 'Critical success factors for implementing knowledge management in small and medium enterprises', Journal of Industrial Management \& Dato Systems 105(3), 261-279, viewed 01 June 2009, from http://www.emeraldinsight com/0263-5577.htm

\section{APPENDIX}

\section{Interview questionnaire}

\section{Section A: Biographical and company information}

1. Name of organisation:

Physical address:

Core business of organisation:

Number of years in existence:

2. Name of Owner, Director, Chief Executive Officer and/or Chief Information Officer:

Number of people working in the organisation:

Categories of staff (e.g. professional, administrative, technical, etc.):

\section{Section B: Knowledge and information sharing practices}

1. Research shows that small and medium-sized enterprises (SMEs) face many challenges, especially in terms of access to finance and attracting and retaining good quality staff. What challenges, if any, does your organisation face?

2. How do you generally communicate with your employees? Do new employees attend an induction session?

3. What do you do to encourage workers to communicate and share knowledge and ideas?

4. If a highly skilled individual should leave your employ, is it a total loss to your company or do you have measures in place to ensure that experienced staff transfer their knowledge to others?

5. How is knowledge and experience shared? What do you do to encourage workers to communicate and share knowledge and ideas?

6. Do you provide training and mentoring for new staff members who join the organisation? If so, how is this done?

\section{Section C: Information needs and knowledge sources}

1. Where do you obtain any required information from? How often do you search for information?
Section D: Management of knowledge and acquisition of external information

1. Do your staff members attend conferences, seminars and forums where they meet and network with peers or competitors?

2. Do you ever consult your competitors or do they (i.e. your competitors) consult you for advice in terms of sharing knowledge?

3. Do you make use of Facebook or Twitter to communicate and share ideas with your colleagues inside and outside of the company?

4. How are staff members encouraged to develop and implement new ideas or express their opinions? What does the company do to make it comfortable for workers to share knowledge?

5. Most of our knowledge is stored in our brains. Nevertheless, how do you store additional knowledge, for example, printed knowledge (i.e. explicit knowledge) such as reports and policies? Do you make use of databases or knowledge repositories?

6. We are often faced with an overload of information in the world today. How do you filter through masses of information in order to get to the right information to ensure effective decision-making?

7. Do you ever determine what knowledge your company requires in order to realise the company strategy?

\section{Section E: The level of competitive advantage}

1. What makes your company special?

2. Do you believe that your company can achieve more in order to gain competitive advantage over competitors?

3. Do you believe that you have the right people in your organisation to achieve a competitive advantage?

4. We know that you have expert knowledge - does this knowledge (and/or the sharing of it) play a role in your achieving a competitive advantage over your competitors?

5. Do you conduct regular market surveys and/or research to find out what the market and customers want?

6. Who are your customers and how important are they to you?

7. What would you consider to be your most important organisational asset or assets?

8. What does your organisation strive to achieve and have you achieved it?

Section F: The combination of knowledge management and competitive advantage practices

1. Because the engineering field is regarded as being projectbased, how do you record and transfer knowledge from one project to another? How is this information captured for future purposes? Where is it located and how can it help to make future decisions?

2. Do you have any knowledge of what your competitors are doing in order to stay ahead and maintain a competitive edge over you?

3. Would you say that your unique knowledge gives you a competitive advantage over your competitors? If so, how?

4. Where do you see yourself and/or your company in 5 years time? 
Examples of previous knowledge management studies that have been undertaken.

Source of previous knowledge management study Uit Beijerse (1999)

Uit Beijerse (2000)

Snyman and Van den Berg (2003)

Kok, Van Brakel and Van der Walt (2004)

\section{Questions asked}

Strategic questions:

1. Does the management of the organisation know what kind of market activities competing companies undertake with regard to the development of knowledge?

2. Does the management of the organisation know what the core competencies of the organisation are in terms of knowledge assets?

3. Does the management of the organisation have a long-term vision about knowledge, which will be required in future? Given this, does the management of the organisation actively try to build a collective ambition regarding this?

4. Does the management of the organisation formulate a short-term and medium-term strategy with regard to the acquisition, sharing and evaluation of knowledge? Given this, has the management formulated a knowledge policy?

Organisational questions:

1. Does the organisation have a knowledge management-friendly organisational structure that facilitates the acquirement, sharing and evaluation of knowledge between (knowledge) workers?

2. Does the organisation have a knowledge management-friendly organisational culture that motivates the acquisition, sharing and evaluation of knowledge between (knowledge) workers?

3. Is the style of management within the organisation such that it stimulates sharing and evaluation of knowledge amongst (knowledge) workers?

4. Is there some kind of integrating knowledge infrastructure within the organisation, which secures the necessary continuing steps to determine knowledge gaps, develop and buy knowledge, share knowledge and evaluate knowledge?

Instrumental questions:

1. Are there instruments within the organisation, which are specifically aimed at the determination of the difference between available and required knowledge?

2. Are there instruments within the organisation, which are specifically aimed at the development of knowledge based on the determination of the knowledge gap?

3. Are there instruments available with which the use of knowledge is (constantly) monitored?

1. Have you ever heard of knowledge management?

2. Would you say that knowledge is one of your most important competitive factors?

3. Do you ever determine what knowledge your company requires in order to realise your company strategy?

4. Do you ever determine what knowledge is present in your company and in the heads of your employees?

5. Have you ever been occupied with the external acquisition of knowledge for your company processes?

6. Do you occupy yourself with developing knowledge with regard to your company?

1. Have you become more aware of the importance of knowledge management and the necessity to share (and capture) knowledge since implementation of the community of practice?

2. Have you benefited from the discussions held in the community of practice?

3. Do you participate in the community of practice by sharing your own knowledge on a specific topic?

4. Would you like to have access to information previously acquired through the community of practice?

1. How often do you share your experience of knowing where to find information with other members of staff via the Internet?

2. How often do you share your experience of knowing who to ask for help amongst other members of staff via the Internet?

3. How often do you share your experience of knowing how to resolve a problem with other members of staff via the intranet?

4. What improvements do you believe can be made to the intranet to make knowledge sharing easier for daily work, projects, departmental information and company information?

5. How easily do you locate information on the intranet that is relevant to your work?

6. How easy is it to publish on the intranet?

7. What type of incentives do you receive in return for your knowledge sharing on the intranet (award and recognition, monetary - part of annual bonus scheme, promotion opportunities, training or educational opportunities, funding for travel and attendance of conferences)?

8. Do you receive the right level of training to participate effectively in knowledge-sharing initiatives on the intranet?

9. Do new employees attend an induction session on how to use the intranet?

10. To what extent does sharing your knowledge via the intranet create new business opportunities?

11. To what extent do new ideas for knowledge management initiatives come from all departments?

12. To what extent do new ideas for knowledge management initiatives come from one department? 